\title{
ABORIGINAL AND ETHNIC COMMUNITIES AND IYC
}

International Year of the Child its impact on Aboriginal child and family welfare and its possible implications for other minority cultural groups are the themes for this editorial.

International Year of the Child is ending. The spotlight is slowly fading on the centre stage. The costumes of the key characters, the children's advocates, the experts, the concerned, are ready to be dismantled and put away. The grand finale has been and gone and the audience tired of the many acts that International Year of the Child has paraded, are getting ready to file out of the theatre.

The cast are now fiercely shuffling for positions in the stage wings. The bids for who should be the main act are now dying echoes in the emptying room - the audience having seen this show now mill out to catch their breath and to work out what the show was all about, and which act should get the rave reviews.

Oh yes, there can't be a successful show without the producers, the organisers and the supporting staff. Now their sights are swiftly turning to the next show they can produce so that the audience will return. But some credit must go to these people because they have ensured that the I.Y.C. act has gone the right way and no-one stepped out of line. Oh yes it was definitely contained, you could say.
Let's look at some of the I.Y.C. key acts. There was Aborigines, Children with special needs, Adoption, Fostering, Parents rights, Childrens rights, Adolescents, etc. who all appeared on the bill. Some become one nite stands, others got longer spots on the show. But when the show closes, the acts either need to fold or look for other alternatives to survive. I guess most acts that I know of are doing the latter.

The reader would by now be anxiously curious about what the above metaphores or analogies represent. I have deliberately looked at the past 11 months of I.Y.C. through a familiar perspective of the stage or theatre. I once heard someone say that an analogy is a useful tool for explanation. "It helps us to explain the unknown." So you can see why I have satirically portrayed the events of I.Y.C. in this manner. There are many parallels between these events and the useful example of the theatre or stage. The common basis is that both involve many events, characters and acts.

I am not suggesting to the reader that now that I.Y.C. is almost over that it should necessarily be forgotten. It has been most significant that there was an I.Y.C. in 1979. But why should it be stressed just for 1979? Have people not always cared about children and their families? I would argue strongly that 1979 should not be seen as the only time that the community was given an opportunity to care about children and their families, but this has been an ongoing process and will continue to be.

Let me now turn my attention to the underlying topics of this editorial theme, namely the impact on Aboriginal Child and Family Welfare and the possible implications for other minority cultural groups.

Those with responsibilities in the area of child and family welfare, particularly how it relates to the Aboriginal community, have become increasingly aware of the failure of predominantly white services and institutions to respond appropriately to the specific needs of Aboriginal people. The main effect of white intervention has been two fold. Firstly, it has resulted in the dislocation and alienation of Aboriginal people from their own culture i.e. assimilationist policies and the forced removal of Aboriginal children from their families. Secondly, it has also created the same feelings towards the dominant white culture of Australian society.

The ramifications of this unwitting intervention disclose their negative influences on many aspects of Aboriginal life. For instance the lack of sensitized policies in hous ing, education, health and welfare has contributed largely to the fragmentation and destruction of the Aboriginal people. 
To tackle these issues in a constructive manner the Victorian Aboriginal Child Care Agency hosted a National Seminar in Melbourne in April this year. Although many broad issues arose out of the seminar which was attended by some 240 delegates representing all the states and territories in Australia, the main focus was on the Aboriginal child and the family. The highlight of the conference was that two overseas keynote speakers from the Association of American Indian Affairs and the Yakima Indian Nation Program in Washington attended, also.

There is now a developing concern in the Aboriginal communities about the plight of the families and more so the children. The seminar acted as a forum where this concern could be expressed and discussed. One of the many conclusions drawn from this discussion was that Aboriginal people themselves need to be involved and actively consulted in the provision of any service delivery to their communities. In many instances Aboriginal people have also shown they can provide services to their people more effectively than exisitng general services can. The Victorian Aboriginal Child Care Agency, Legal Services, Health Services and Welfare Services are such examples.

One of the clear messages from the seminar which is also applicable to the question of service delivery systems is the question of problem definition and solution definition.
There needs to be a greater involvement of Aboriginal people in the definition of their problems rather than someone from outside doing this for them. Not only do Aboriginal people have to be involved there, they also need to actively participate in the solution definition process also. This then completes the nexus between problem and solution. Too often in past policy making, there has been a gap between problems and solutions. Too often have the wrong solutions been applied to the problem definition. It's like saying that 3 is the product of $1+1$.

However when the questions of Aborigines providing their own services or the involvement of Aborigines in decisions effecting their lives are raised, there are generally two predictable responses. In regard to the first question the response is usually the fear of separatism and/or apartheid. But when we go to our historians to see what policies the government operated under in the past we find that Aborigines were at once deliberately segregated from the broader community. In regard to the second question the response is one of threat. Usually of one's perceived territory or God given right to make decisions over the lives of Aborigines.

In my experience with the Aboriginal Child Care Agencies, after much personal negotiation and continued pushing we have managed to put to rest on most occasions

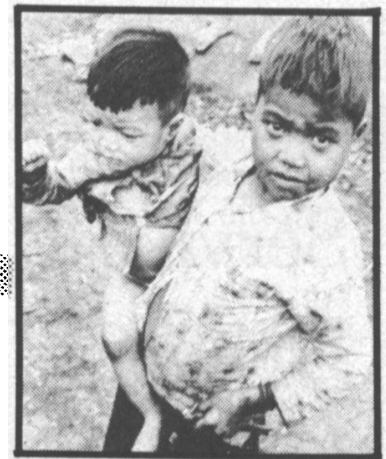

the above fears in peoples' minds and hearts.

In rounding up this discussion let us look at some of the possible implications of I.Y.C. on the other minority culture groups. I must first preface my remarks by saying $I$ do not profess to speak as an expert in this area. It is reasonable to suggest that there are some parallel difficulties which minority cultures, particularly ethnic groups, confront as do Aboriginal communities. For instance, language, custom, lifestyle, etc. are some of the factors which effect the group or community's access to community services.

Similarly with the Aboriginal peoples' push to be involved and to have some say in the decisions which effect their lives, there also appears to be a move in that direction by other minority groups. I.Y.C. has in a way made it possible for the above issues to be discussed and appreciated more widely. But I am still concerned that as the year draws to an end that the discussions, proposals and support will fade away. I do hope I am proven wrong here and that the enthusiasm and commitments made this year to community groups will continue to grow.

Graham Atkinson, B.S.W. Aboriginal Social Worker, Victorian Aboriginal Child Care Agency, 5 Brunswick Street, FITZROY. 